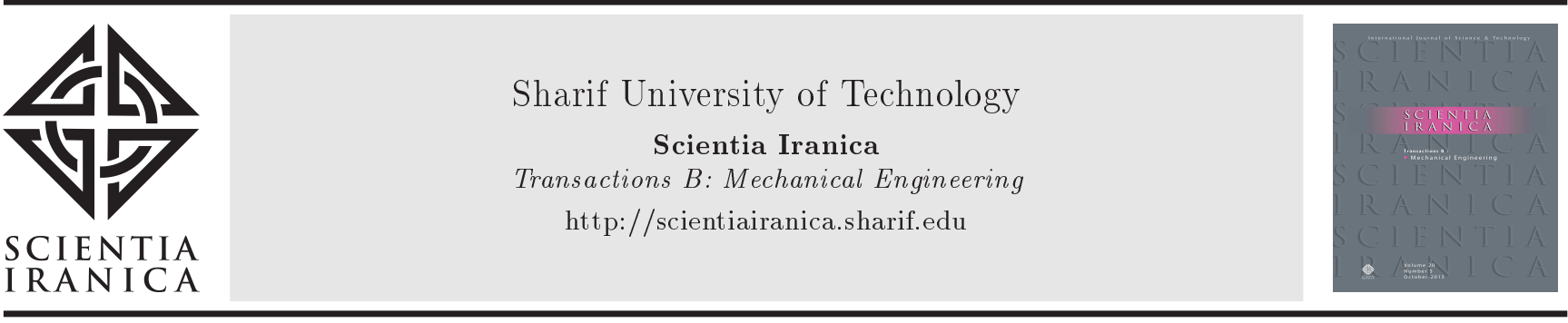

\title{
Experimental investigation of open-hole compression strength of carbon epoxy composite material and determination of localized strains using digital image correlation technique
}

\author{
M. Tayyab, M. Imran*, and A. Rafai \\ Department of Mechanical Engineering, International Islamic University, Islamabad, Pakistan. \\ Received 23 October 2020; received in revised form 8 February 2021; accepted 17 May 2021
}

\author{
KEYWORDS \\ Composite materials \\ strength; \\ Carbon epoxy \\ composite; \\ Digital image \\ correlation; \\ Carbon fibers; \\ Compression strength.
}

\begin{abstract}
Fiber-reinforced composites are widely known for their application to military and commercial aircrafts, in which the weight reduction is required to ensure higher speeds and increased payloads. Carbon fibers, either alone or with the Kevlar 49 fibers, are widely used as the main materials in many aero plane wing, fuselage, and empennage components. Composite materials have many applications in different industries owing to their very different properties from those of metals and polymers. While drilling the carbon/epoxy composites, the cut surface quality highly depends on the drilling parameters set during drilling which further affects the strength of the hole during extension/compression loading. In this study, Carbon Fiber Epoxy Composite (CFEC) material was drilled using the standard carbide drill bit, and Open Hole Compression (OHC) tests were carried out on the Universal Testing Machine. In addition, Digital Image Correlation (DIC) technique was employed to find out the strain distribution around the hole during compression loading. Based on the experimental method and DIC, the maximum strength of the carbon epoxy composite was achieved by drilling at $1600-2400 \mathrm{~mm} / \mathrm{min}$ in the presence of notch. It was also observed that failure of the structure was dependent on the drilling feed rate and the optimized drilling range was $1600-2400 \mathrm{~mm} / \mathrm{min}$.
\end{abstract}

(C) 2021 Sharif University of Technology. All rights reserved.

\section{Introduction}

Fiber-reinforced composite materials are generally formed by the fibers of high strength and modulus bonded together with a matrix in the form of interfaces (boundary). The physical and chemical identity of the constituents (fiber and matrix) remains the same in the composite material; however, a combination of

\footnotetext{
*. Corresponding author.

E-mail address: Muhammad.imran@iiu.edu.pk (M. Imran)
}

doi: $10.24200 /$ sci. 2021.57044 .5034 properties cannot be attained by any one constituent only. Fibers are the main components of any composite and function as load-carrying members while the matrix binds the fibers together, keeps them with a proper orientation, and acts as a protective medium for the fibers. The applications of composites are so extensive that it is impossible to list them all. The major applications of mentioned composites are in the industries such as aircraft, space, automotive, sporting goods, and marine engineering, to name a few [1]. The main purpose of composites in engineering is weight saving. Some of the major applications are briefly discussed in the following. 
The most significant application of the fiberreinforced composites is in the field of military and commercial aircrafts, in which weight reduction is required to ensure higher speeds and increased payloads. Carbon fibers, either alone or with the Kevlar 49 fibers, are widely used as the main materials in many aero plane wing, fuselage, and empennage components [2-5]. Fiber-reinforced epoxies are widely used in helicopter rotor blades to reduce the weight and tailor the dynamic frequencies of the blade. Since weight reduction is vital to space vehicles, many composite materials are employed including boron fiber-reinforced aluminum tubes for the mid-fuselage truss structure and aluminum honeycomb in combination with the carbon fiber-reinforced epoxy face-sheets for the payload bay door [6,7]. Another reason why the composites are preferred over the metals is because of their thermal stability over a wide range of temperature changes.

In the automotive industry, composite materials can be categorized into three groups: body components, chassis components, and engine components:

a) In the exterior body components, such as hood or door panels, demand high stiffness and damage tolerance (dent resistance). Damage tolerance is achieved using exible resins and polyurethanes;

b) In chassis components, the composites were first used in the leaf spring using uni-leaf E-glassreinforced epoxy, which replaced the ten-leaf steel spring with nearly $80 \%$ weight saving;

c) In the development process, composites are applied in the engine parts. Of note, the challenging area of application for which different composites should be developed is fatigue loading conditions at very high temperatures [8].

Over the last few years, the application of fiberreinforced polymeric composites in the sporting goods has substantially increased for several advantages including weight reduction, vibration damping, and design flexibility [9]. As a result, some major products can be made namely tennis rackets, golf club shafts, fishing rods, bicycle frames, snow and water skis, hockey sticks, oars, surfboards, arrows, helmets and athletic shoe soles, and heels. Glass-fiber-reinforced polyester laminates are widely used in marine applications; however, nowadays, Kevlar 49 is replacing the glass fiber in some of the applications because of their higher tensile strength-weight and modulus-weight ratios than the glass fiber. They are widely used in boat hulls, decks, bulkheads, frames, masts, and spars. As a result, as weight reduction is observed which, in turn, increases the cruising speed, acceleration, and fuel efficiency.

A wide range of fibers are used as reinforcements in composite materials [10]. While fibers are classified based on their lengths as short and long, continuous fibers are categorized based on their strength and stiffness or by their chemical composition as organic and inorganic. Commonly used fibers in inorganic category are glass, carbon, boron, ceramic, mineral, and metallic. The organic fibers are usually made of polymeric material. Determining the fiber type is a tradeoff among the many properties such as mechanical, environmental, and cost [11-14]. Carbon fibers, also called graphite fibers, are widely applied in the aerospace industry due to their light weight and strong fibers with excellent chemical resistance. The mechanical properties of carbon fibers can be identified through the atomic structure of carbon molecule chains and inter linkages. The strength of carbon fibers can be altered by the orientation of carbon atomic structures with their strongest atomic bond along the carbon fiber direction.

The properties of carbon fibers depend on the used raw material and manufacturing process, including two main categories of raw materials are Polyacrylonitrile (PAN) and Pitch. Pitch fibers are cheaper and usually less strong than the PAN. Unlike the glass fibers, carbon fibers are available with a broad range of stiffness values. The stiffness of fibers can be controlled by the thermal treatment of both PAN and Pitch-based carbon fibers. The thermal treatment actually affects the carbon content and orientation of the strongest carbon links along the fiber direction. The main driving force behind using high-modulus fibers is to make composite that can replace steel or aluminum, hence a substantial reduction in part weight. For instance, a composite material with a $50 \%$ fiber volume fraction of M50 fibers has approximately the same stiffness as that of steel with one-fourth of the weight.

The maximum operating temperature of carbon fibers varies from $315^{\circ} \mathrm{C}$ to $537^{\circ} \mathrm{C}$; however, this limit is further affected by the operating temperature of the matrix. Since carbon fibers are stiffer than glass fibers, they provide the composites with better fatigue characteristics by reducing the amount of strain in the polymer matrix in a given loading condition. However, carbon fibers are subject to such limitations as low shock resistance due to their high rigidity and high fragility as well as the possibility of chemical attack in the presence of oxygen and other oxidizing agents. Galvanic corrosion is another factor that takes place in case the carbon fiber composite is in electrical contact with metals and their good electrical resistance. Therefore, an electrical barrier like glass fiber material is required to avoid the direct contact between the carbon fiber composite and the metal. The major limiting factor in applications of carbon fiber composite is the cost. The costs of using carbon fiber composite can be justifiable only when weight savings offer large payoff as in aerospace applications and also, when 


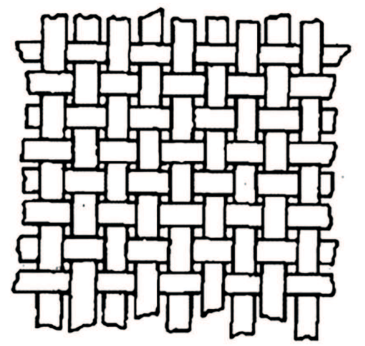

(a)

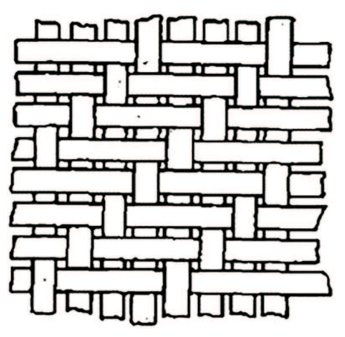

(b)

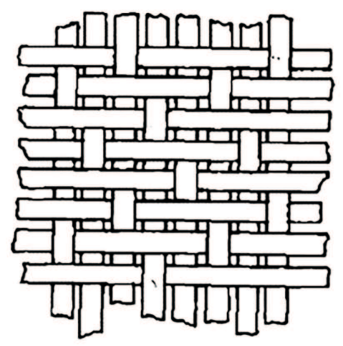

(c)

Figure 1. (a) Plain weave. (b) Twill weave. (c) Satin weave.

high temperature performance, corrosion resistance, improved fatigue strength, or long-term retention of strength constitute the necessities of a specific application. Cost savings for carbon fiber composite can be achieved by part integration as well as reduced installation and maintenance costs [15].

While continuous and discontinuous reinforcements for composites are very common to apply, textile reinforcements provide greater strength and enhance the performance while reducing the overall manufacturing cost. The process of resin transfer molding is particularly designed for woven fabric reinforcements. Composite designs depend on the thread design and manufacturing in which the properties of threads can directly determine the overall performance of the composite [16]. For example, an increase in the thread twist reduces its modulus and improves the fatigue properties of the composite. The textiles types can be classified based on the textile design and manufacturing process, as described in the following:

- 1D textile or individual thread: It is also called strand, tow, end, yarn, or roving;

- 2D textile or fabric: It uses the $1 \mathrm{D}$ threads on different patterns on a surface. The resulting plate with a shell-like shape is called 2D structure;

- 3D textile: It uses 1D textile, arranging the threads in a complex 3D formation using different textile processing methods. The resulting material features a $3 \mathrm{D}$ structure [17].

A wide variety of textile fabric forms can be used as reinforcements for composite materials. The simplest and most inexpensive form is the nonwoven fabrics. A nonwoven fabric, called the mat, usually constitutes the randomly oriented chopped fibers such as chopped strand mat, randomly oriented short fibers, or swirled tows or roving. The other form is Continuous Strand Mat (CSM) formed by continuous tows or roving swirled on a flat surface and pressed or loosely held together with a very low amount of binder. Sometimes, a thin mat, known as veil, is used as a surfacing medium for enhancing the corrosion resistance of the composite material. The veil layer is smooth and usually without the textured appearance of the fabric. It serves the purpose of appearance enhancement by hiding the underneath fabric structure.

The woven fabric is a two-dimensional plane surface made from weaving the yarns in a weaving machine. Properties of the woven fabrics are usually of lower quality than those of the unidirectional continuous fibers. The yarn is woven by interlacing along the two orthogonal directions. The yarn held along the weaving direction is called warp yarn, and that perpendicular to the direction of weaving is called the fill or weft yarn. Balance of properties can be obtained using the same yarn in the warp and weft direction, called the biaxial woven fabric. The structure of the biaxial woven fabric is characterized by different types of patterns, the most common of which are plain, twill, and satin weaves, as illustrated in Figure 1. Different patterns of the weave are responsible for different properties of the fabric and the composite [17].

The matrix material binds together the fiber layers and transfers the forces from external sources. It carries some stresses namely transverse, intralaminar shear, and bearing stresses. Important properties such as transverse stiffness and strength largely depend on the matrix selection. Properties of the matrix determine the service conditions of composite which include temperature range, chemical resistance, abrasion resistance, weathering capability, electrical conductivity, and some external characteristics such as appearance. Matrices are of different types like polymers, metals, or ceramics. Polymers are most widely used due to the feasibility of manufacturing complex shapes with low tooling and low capital. Matrix properties depend on the range of temperature bearing capabilities of the matrix.

The performance of the composites varies drastically when it approaches or exceeds the temperature limits. Thermoset polymer matrices such as polyester resins and epoxy resins lose modulus and their ability to transfer load when exposed to alleviated temperatures. Ceramic matrices self-destruct themselves when subjected to cryogenic conditions. Advanced Composite Materials (ACM) are more expensive materials with high performance and those that are employed in 
the field of aerospace mostly comprise carbon-epoxy and carbon-thermoplastic systems. Fiber-Reinforced Plastics (FRP) are usually less expensive materials used in consumer goods and mass markets, mainly comprising fiberglass-polyester systems. Different types of thermoset matrices are polyester resins, vinyl ester resins, epoxy resins, and phenolic resins [17].

Epoxy resins are widely utilized due to their versatility, highly mechanical properties, and high corrosion resistance. Shrinkage of epoxies is very lower than that in other materials ( $1.2-4 \%$ by volume). An epoxy resin has a very attractive property of curing in a wide range of temperatures from 5 to $150^{\circ} \mathrm{C}$. One of the main applications of epoxies is in the aircraft industry in which they are used as adhesive for honeycomb structures and laminating resins for missiles and airframes for filament wound structures and tooling. They are used as body solders and caulking compounds for building and repairing plastic and metal boats and automobiles.

Epoxy resins are applied in fabricating short-run and prototype molds, stamping dies, patterns, and tooling. As insulating materials, they are widely used in electrical insulation as well. The cost of the epoxy resins is justified in comparison with the performance of the resin that varies over a broad range, but it is more expensive than other resins like vinyl esters. Epoxy matrices can withstand the temperature limit of $175^{\circ} \mathrm{C}$. To increase the stiffness of the resin and composite, thermoplastic additives are incorporated and the service temperature is also reduced compared to the brittle epoxies up to $125^{\circ} \mathrm{C}[17]$.

\section{Literature review}

In this section, a review of the studies on the Open Hole Compression (OHC) strength of the carbon fiber composite material is given. The data were collected to represent the historical background of drilling composites as well as its effects on such parameters as thrust force, delamination effect, fiber/resin pullout, excessive tool wear, OHC strength, etc.

\subsection{Various composite drilling findings}

Back in the year 1990, Malhotra worked on the glass fiber/epoxy and carbon fiber/epoxy laminates. The material was cut by high-speed steel and Tungsten carbide coated drills. The main parameters under observations included cutting speed, feed and number of holes machined on the tool wear, and thrust and torque. According to the findings in this study, tool wear increased based on the number of holes and flank wear was higher than chisel edge wear. Carbide drills considerably outperformed High Speed Steel (HSS) drill bits on both materials. Tool wear was greater in the Carbon Fiber-Reinforced Polymer (CFRP) than that in Glass Fiber-Reinforced Plastic (GFRP), mainly because of the higher abrasiveness of carbon fibers than that of the glass fibers [18].

In 1990, Tagliaferri et al. discovered the effect of machining parameters on the cutting quality and mechanical behavior of GFRP composites. The lower ratio of speed and feed resulted in poor cut quality. The limit of ratio is independent of resin type, fiber format, composite thickness, and fabrication method. The tensile strength of GFRP containing hole does not play a role in the extent of the damage. The material exhibits maximum bearing strength for slower drilling speeds [19].

In this study, chip formation and machinability assessment were investigated comparatively with metal cutting. A study of the reinforced thermoset and thermoplastics was conducted to characterize their response to machining. According to the formed cutting chips, the carbon fiber-reinforced thermoplastics presented considerable deformation in chip formation due to the tendency of carbon fiber-reinforced thermosets to fracture. Thermoset-based composites require larger cutting force due to their higher strength and are more responsive to chip size because of their sensitivity to micro defects in fracturing chips. A mathematical model was established to predict torque and thrust in drilling composite materials as a function of cutting parameters and material strength [20].

In 1995, Caprino and Tagliaferri conducted a study on the damage development in drilling GFPR and found that the quality of the cut surface was strongly dependent on the appropriate drilling parameters. Tests were carried out on glass-polyester composites using HSS drill bit. The research further revealed that damage induced in a composite material during drilling was totally dependent on the feed rate of the drilling; in other words, at high feed rates, the failure modes were more likely to cause damage, with steps like delamination, intralaminar cracks, and high-density micro failure zones [21]. In 2000, Piquet et al. conducted an experimental analysis of drilling damage in a thin carbon/epoxy plate using special drills. Drilling tool geometry plays an important role in determining the drill quality. To perform a conventional double fluted twist drill, it is necessary to make a pre-drill hole to neutralize the chisel effect. Machining conditions can be further improved by variable feed rates on CNC drill [22].

Lachaud et al. conducted a study on the drilling of composite structures in 2001. The model was established to illustrate the relationship between the thrust force of the drill and localized bending of the last few plies. The penetration and delamination conditions of the last few plies were assessed [23]. Davim and Reis (2003) carried out an experimental and statistical study on drilling carbon FRP manufactured by autoclave. In 
this respect, "Straight shank" drill had lower power and specific cutting pressure than "Brad \& Spur". The feed rate is the cutting parameter that has greater influence on the power for both drills. Power increases with velocity and feed rate. Delamination level was also high at a high cutting speed and high feed. The feed rate was the cutting parameter with the slightest impact on delamination during entrance on CFRD [24].

Bhatkulkar and Modak evaluated the effects of drilling on unidirectional GFPR. Depending on the drill point angle and feed rate, the thrust force increased with an increase in both point angle and feed rate. It was statistically proven that while using ANOVA, the drill point angle, feed rate, and their interactions could significantly affect the drilling forces. The torque decreased upon increasing the drill point angle for all feed rates [25].

Rajmohan and Palanikumar assessed the application of central composite design for optimizing the machining parameters in drilling hybrid metal matrix composites. A mathematical model was presented to predict the values for thrust force, surface roughness, and burr height. Analysis of variance (ANOVA) technique confirmed the existence of cracks, particle pullout, and shearing of particles [26].

Sadek et al. (2012) conducted a study on the Orbital Drilling (OD) of woven carbon fiber-reinforced epoxy laminates. The emerging process of OD can greatly reduce or eliminate the defects associated with the drilling of composites, e.g., delamination and thermal damage. The axial force was reduced in OD and produced delamination-free holes. High speed and high axial feeds are still regarded as challenges in OD [27].

Phadnis et al. experimentally evaluated the effects of damage on the carbon/epoxy composite. Critical modes of damage in CFRP were experimentally quantified based on the obtained micro-tomography images after image processing. The Finite Element (FE) model predicted the drilling thrust force and torque with reasonable accuracy, compared to experimental results. It was observed that the damages resulting from thrust force, torque, and delamination increased abruptly with an increase in the feed rate; however, they were gradually reduced upon increasing the cutting speeds. The numerical studies indicated that low feed rates $(<150 \mathrm{~mm} / \mathrm{min})$ and high cutting speeds $(>600 \mathrm{rpm})$ were ideal for drilling carbon/epoxy laminates [28].

Karimi et al. experimentally evaluated the effect of drilling parameters on the thrust force, adjusted delamination factor, and compressive residual strength of drilled laminates. The parameters including drill point angle, cutting speed, and feed rate at three levels were used based on the Taguchi method. Acoustic Emission (AE) technique was also employed as an intelligent method for monitoring the drilling and compression test. The feed rate was shown to have a direct effect on the delamination factor. In addition, compressive residual strength was at its highest level on low feed rates, and the effects of drill point angle and cutting speed were almost negligible. AE can be used as a tool for detecting failure mechanisms before happening; of note, without damage, no AE signal occurs [29].

In 2013, Durão et al. found that the drilling process that reduced the drill thrust force could lessen the risk of delamination. The delamination assessment methods based on radiographic data were compared and correlated with the mechanical test results. Unidirectional carbon fiber/epoxy laminate plates were drilled with the objective of comparing the performance of three different tool geometries combined with three feed rates. The higher feed rates correspond to higher delamination extension. For HSS drill, despite the fact that damage region was higher, carbide drills had no effect on tool geometry. The plates drilled by carbide twist drill and lower feed rate were of higher strength [30].

Feito et al. (2014) investigated the FE modeling for drilling of CFRP composites to perform damage prediction. Computational expenses of these complex models are regarded as one of the main disadvantages compared to simplified models that consider the drill acting as a punch that pierces the laminate of composite. Two different approaches were employed to develop the model: a) complete modeling of drilling in which the feed and rotation movements of the drill were developed and b) a simplified model in which the drill acts like a punch. This model can slightly overestimate the value of delamination factor. The results are significant, especially when the complexity and calculation expenses of both models are compared. While simulations can be solved in several minutes, the complete model requires several days [31].

In 2014, Qi et al. studied delamination during drilling metal-FRP stacks with the effect of metal stack in drilling. Two cases were taken into account in this research: drilling direction during drilling metalFRP stacks and drilling from metal to FRP and FRP to metal. The mechanical models for predicting the Critical Thrust Force (CTF) were established based on linear fracture mechanics, classical bending plate theory, and mechanics of composites. Delamination will not occur during drilling from FRP to metal when the thickness of the metal plate exceeds the critical thickness, regardless of the drilling process parameters [32].

Goutianos et al. examined the microscopic compressive behavior of unidirectional CFRC. The main focus was placed on ensuring a better understanding the effect of fiber damage in compression of adjacent fibers as well as fiber and matrix interfacial properties. The results obtained from experiments and numerical 
Table 1. Open hole compression strengths.

\begin{tabular}{lccccccccc}
\hline Specimen \# & S1 & S2 & S3 & S4 & S5 & S6 & S7 & S8 & S9 \\
\hline OHC strength $(\mathbf{N})$ & 26013 & 21837 & 24795 & 26448 & 23403 & 22359 & 25143 & 25839 & 21315 \\
\hline
\end{tabular}

solutions revealed that the compressive failure of high modulus carbon fiber composites resulted from the compressive response. Shear failure in fibers is indicative of the higher stress transfer rate in compression. In short, it can be concluded that the relation between stress and strain is linear given the low compressive stress whose behavior deviates as the compressive stress increases [33].

Suemasu et al. conducted a numerical and experimental study to find $\mathrm{OHC}$ damage initiation and propagation in quasi-isotropic composite laminates. Experiments were carried out using OHC testing fixture suggested by National Aerospace Laboratory (NAL III). In this study, the damage began unstably first and then, became stable after the stabilization of propagation trend [34]. Saha et al. conducted an Open Polturated Hole (OPH) test using the testing setup of Institute for Aerospace Research. Studies have investigated the effects of the hole size on the compressive strength of E-glass fiber composite sheet made by pultrusion using isophthalic polyester resin matrix. It was found that the strain at hole edges increased upon increasing the hole diameter. Micro fiber bulking and shearing between layers were also observed [35].

Poon et al. carried out $\mathrm{OHC}$ tests for laminates and numerical simulations to investigate the damage propagation in compression using Material Testing Systems (MTS) testing machine and fixture suggested by Institute of Aerospace Research. In case the ultimate failure load reaches $90 \%$, the compressive damage occurs. Furthermore, it was concluded that with an increase in the number of plies in laminate strain, initial failure would decrease [36].

Zako et al. conducted a numerical study and found that stress concentrations at geometrical discontinuities resulted from compressive loading. Here, stress increased at geometrical discontinuity such as holes and it was used to determine the material strength of the composites using $\mathrm{OHC}$ test. Tri-axial stress was produced from any discontinuity within laminates of specimen [37]. Carvalho et al. conducted several experiments and simulations to find compressive damages to orthogonal orderly stacked and randomly stacked $2 \mathrm{D}$ woven composites. They also found that the strain behavior for both types of materials was quite different. In orderly stacked 2D composites, delamination and yarn bending, besides cracking, were also significant [38].

\subsection{OHC strength of the composite specimens} The OHC strength can be measured through the following stress formula [39]:

$$
F_{x}=P_{\max } / A
$$

where:

$F_{x} \quad$ Ultimate open hole compressive strength of specimen $(\mathrm{MPa})$

$P_{\max } \quad$ Maximum force before failure (N)

A Gross cross-sectional area (without considering hole) $\left(\mathrm{mm}^{2}\right)$

The total cross-sectional area of the specimen is $2.90 \times 30 \mathrm{~mm}$, which is equal to $87 \mathrm{~mm}^{2}$. The values of $\mathrm{OHC}$ strength are given in Table 1.

\section{Experimental methodology}

The adopted test method was D6484/D6484M which is a standard test method of ASTM for measuring the OHC strength.

\subsection{ASTM standard D6484/D6484M}

This test method is used to determine the OHC strength of multidirectional polymer composites. Limitation of this testing standard indicates that it is valid only for continuous and discontinuous fibers (tape or fabric, or both), and the laminate should be balanced and symmetric along the test direction while performing this test. The objective of this test method is to estimate notched compressive strength data for the structural design, material specifications, and research and quality assurance [40].

\subsection{Testing procedure}

The uniaxial compression test was performed on the balanced symmetric composite specimens with a hole in the center. The extensometer can also be used to determine the displacement. The ultimate strength of the specimen was calculated in the gross cross-sectional area regardless of the existence of the hole. The hole causes stress concentration which is very common in aerospace notched designs due to the assembly of different parts.

The face of the test specimen is supported by a fixture presented in Figure 2. In this fixture, the specimen is placed inside the fixture bolted to be held, and the shear loading is transmitted during the compression test. The fixture is placed in the two 
flat platens, and the compression force is applied and transferred from fixture into the test specimen. The dismantled fixture for ASTM D6484/D6484M is shown in Figure 2.

The two pieces of the fixture are joined by the supporting plates and bolt. Figure 3 shows different parts and assembly of fixture.

The drilling parameters were selected from a study conducted by Davim and Reis [24]. These parameters are shown in Table 2.

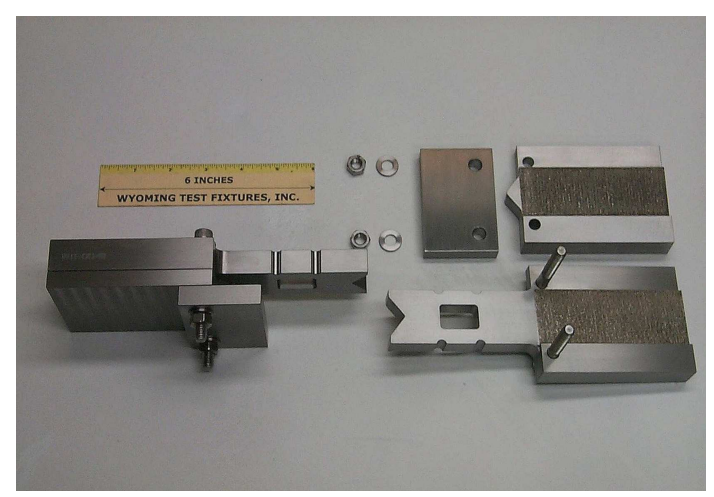

Figure 2. Test fixture disassembled view.

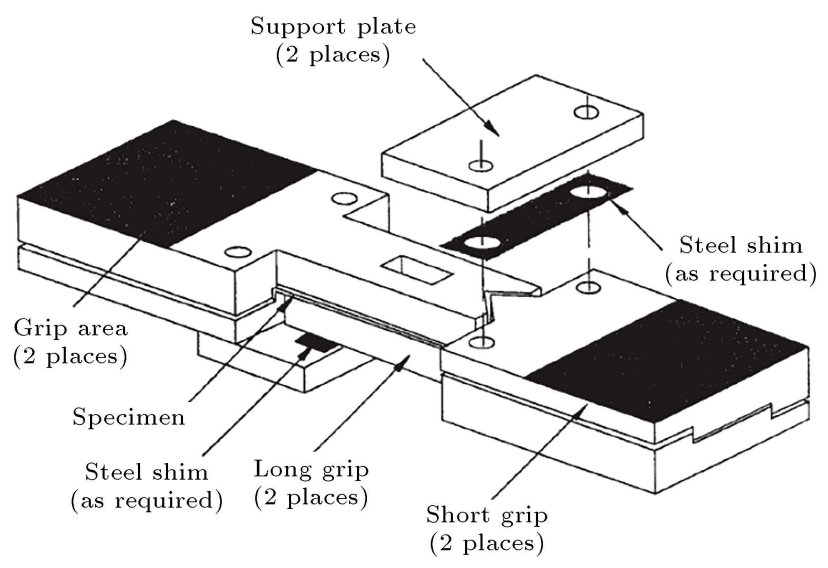

Figure 3. Test fixture different parts in assembly view.

Table 2. Drilling parameters.

\begin{tabular}{cccc}
\hline Sr. \# & Specimen \# & $\begin{array}{c}\text { Speed (S) } \\
\mathbf{m m} / \mathbf{m i n}\end{array}$ & $\begin{array}{c}\text { Feed (F) } \\
\mathbf{m m} / \mathbf{m i n}\end{array}$ \\
\hline 1 & $1,10,19$ & 1600 & 64 \\
2 & $2,11,20$ & 1600 & 192 \\
3 & $3,12,21$ & 1600 & 480 \\
4 & $4,13,22$ & 2400 & 64 \\
5 & $5,14,23$ & 2400 & 192 \\
6 & $6,15,24$ & 2400 & 480 \\
7 & $7,16,25$ & 3200 & 64 \\
8 & $8,17,25$ & 3200 & 192 \\
9 & $9,18,27$ & 3200 & 480 \\
\hline
\end{tabular}

\subsection{Failure modes}

The acceptable failure modes of the ASTM standard D6484/D6484M are shown in Figure 4 [40].

\subsection{Specimen preparation for DIC}

In order to apply Digital Image Correlation (DIC) technique to the composite specimens, they should be prepared with a random pattern grid, also known as speckle pattern. To this end, since the specimen materials are made of carbon fiber and are originally black, white color was utilized to make random patterns on them; otherwise, they should be colored black first before making the random white dotted speckle pattern on it. To make random dot patterns, teeth brush was utilized which was dipped in the white paint, its fibers were pulled and released to sprinkle the paint dots on the specimen, and this process was repeated until achieving the required grid of speckle pattern on the specimen surface. The specimen with the dotted pattern is depicted in Figure 5.

The testing was conducted on the Super L- 200KN Trinius Olsen (American manufactured) universal testing machine at the material testing laboratory at School of Chemical \& Material Engineering, NUST H12, Islamabad.

In the experiment, a test fixture was utilized to hold the specimen in the vertical position and avoid the bucking effect in the specimen. The shear load was then vertically applied to the specimen. The shear

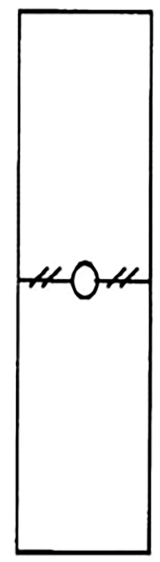

(a)

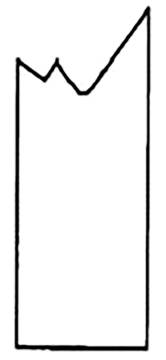

(b)

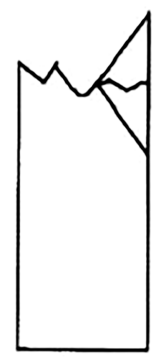

(c)
Figure 4. Failure modes in compression test: (a) LGM, (b) AGM, and (c) MGM.

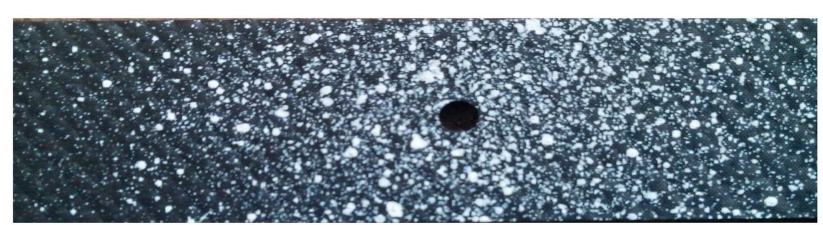

Figure 5. Image prepared for Digital Image Correlation (DIC). 
force was transmitted to the specimen. The specimens were already prepared for the DIC. For DIC setup, a Kodak Eassy Share M 340, 16-mega pixel standard digital camera was used to capture video during the testing of composite specimens. A Velborn $\mathbb{R}$ tripod was also employed to position the camera in front of the fixture for smooth video capturing. The light was sufficient in the laboratory environment to illuminate the specimen surface; therefore, no extra light was required for video capturing.

Load was gradually applied to the fixture, and values were recorded in the data acquisition system of the machine using Intel Pentium IV processor. Values obtained from the machine are depicted in the form of stress-strain points. The data acquisition system of the machine also plots the stress-strain behavior of the composite material.

During testing, a video of the experiment applying the DIC technique was made. The digital camera was fixed on the tripod in front of machine close to the fixture so that it can capture displacements in the specimen. The recorded video was then converted into digital images by extracting the frames from the vide using digital image processing tool box in the MATLAB 2012b@. DIC technique was applied using GUI developed by Elizabeth Jones in MATLAB 2012b@ in August 2013 at University of Illinois, Chicago, USA [40]. The experimental setup is shown in Figure 6 .

\subsection{Digital Image Correlation (DIC)}

The conventional method used for determining the material properties was established using extensometers. This method provides only average strain on the total gauge length of the specimen, not after the necking. DIC technique can be applied to obtain high-accuracy strain results. Owing to the fast data acquisition system, this technique can be used to find material properties in elastic and plastic ranges. This technique is also helpful in full field, non-contact, and high accuracy determination of displacement and strain measurement [41].

\subsection{MATLAB code for $D I C$}

In the DIC technique, MATLAB code was used and developed by the Elizabeth Jones of University of

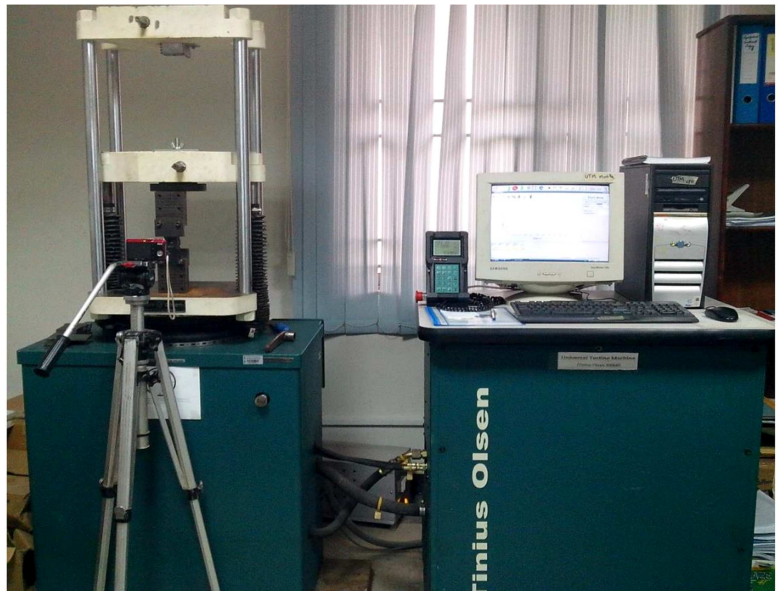

Figure 6. Experimental setup for compression test and Digital Image Correlation (DIC).

Illinois, USA [40]. The video was recorded during the compression tests of the carbon epoxy fiber reinforced composite on the Universal Testing Machine by the digital camera. The images were extracted from the video using the MATLAB. The format of the images was JPG used for image processing in the MATLAB code.

\section{Results and discussion}

The carbon epoxy composite specimens were tested on the 300 KN Tinius Olsen's Universal Testing Machine at the Material Testing Laboratory at School of Chemical \& Materials Engineering, NUST H-12, Islamabad. The objective of testing was to find the compressive failure load of the specimens. The total number of specimens was 27 and a set of 9 specimens drilled on 9 different parameters.

The result from Specimen 1, shown in Figure 7 in the stress-strain graph, represents three trends: trend 1 shows the elastic behavior; trend 2 the stress-strain relationship; and trend 3 the strain at $0.2 \%$. The total strain produced in Specimen 1 is $1.015 \%$.

The stress strain graph for Specimen 12 is shown in Figure 8, according to which the stress value is $281 \mathrm{MPa}$ and the total strain produced is $0.845 \%$. The mean strain of specimens is shown in Table 3 , and the

Table 3. Mean strain of specimens.

\begin{tabular}{cccccccccc}
\hline Specimen \# & S1 & S2 & S3 & S4 & S5 & S6 & S7 & S8 & S9 \\
\hline 1st run & 1.015 & 0.736 & 1.353 & 0.705 & 0.901 & 0.618 & 0.707 & 1.006 & 0.824 \\
2nd run & 0.893 & 1.198 & 0.845 & 0.834 & 0.914 & 0.837 & 0.933 & 0.78 & 0.734 \\
3rd run & 0.926 & 1.101 & 1.341 & 1.589 & 0.744 & 1.339 & 0.878 & 1.093 & 0.734 \\
Mean stresses & 0.944 & 1.011 & 1.179 & 1.042 & 0.853 & 0.949 & 0.839 & 0.959 & 0.764 \\
\hline
\end{tabular}




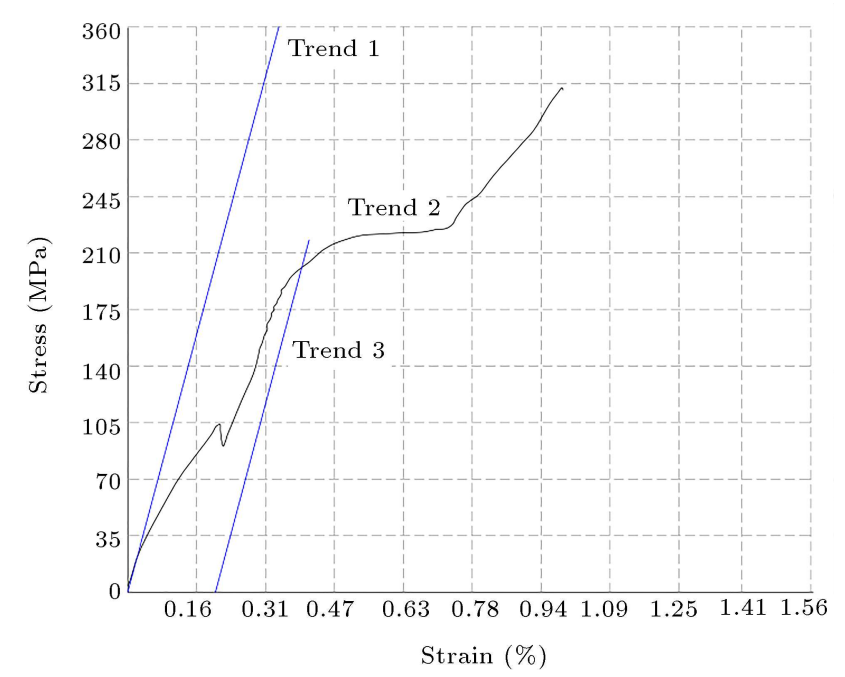

Figure 7. Stress-strain plot of Specimen 1.

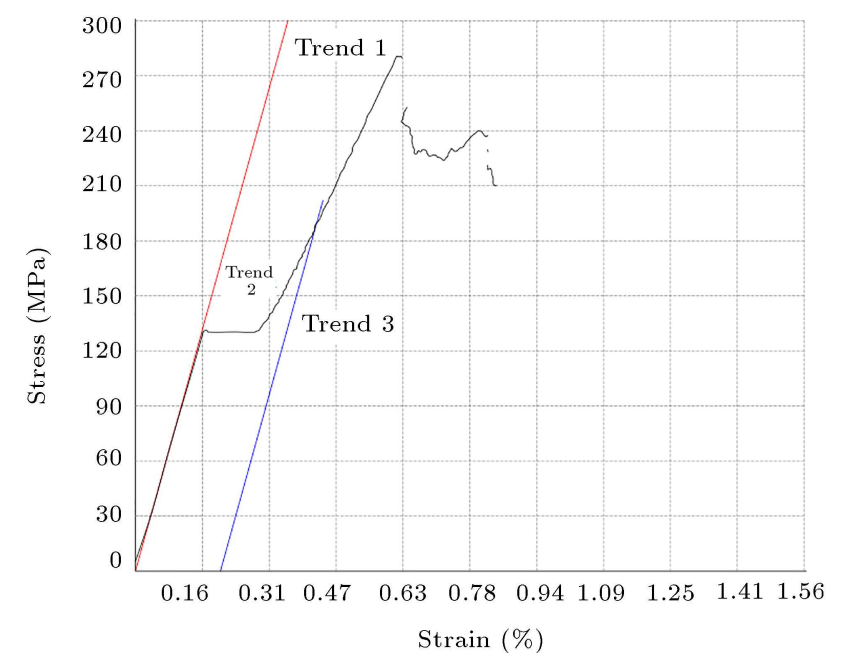

Figure 8. Stress-strain plot of Specimen 12.

mean stresses of the composite specimens are given in Table 4.

\subsection{Comparison of drilling parameters with the $\mathrm{OHC}$ strength}

There are three drilling speeds of 1600,2400 , and 3200 and three feed rates of 64,192 , and 480 . Table 5 shows a combination of these speeds and feeds as well as the comparison with $\mathrm{OHC}$ strength.

In Figure 8, trend 1 is indicative of the speed $1600 \mathrm{~mm} / \mathrm{min}$; trend 2 represents the speed of 2400

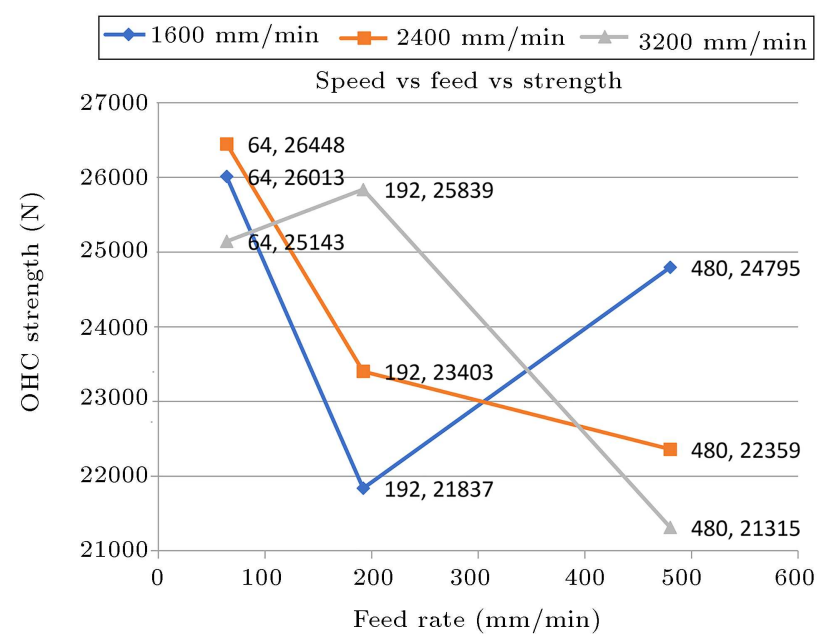

Figure 9. Relationship of speed, feed, and Open Hole Compression (OHC) strengths of Specimen 1.

$\mathrm{mm} / \mathrm{min}$; and trend 3 shows the speed of 3200 $\mathrm{mm} / \mathrm{min}$. The three speeds, feeds, and OHC strength relation are plotted in Figure 9 .

\subsection{Comparison of $\mathrm{OHC}$ strength with delamination}

Table 6 represents the comparison between the $\mathrm{OHC}$ strength and delamination produced due to the drilling of the specimens. As demonstrated by the results, the $\mathrm{OHC}$ strength is maximum on the lower feed rates at $64 \mathrm{~mm} / \mathrm{min}$ for all the three speeds of 1600, 2400, and $3200 \mathrm{~mm} / \mathrm{min}$ and strength drops to $21315 \mathrm{~N}$ at speeds of $3200 \mathrm{~mm} / \mathrm{min}$ and $480 \mathrm{~mm} / \mathrm{min}$. The images presented in Table 6 represent maximum strength where delamination is lower on Specimens 1, 4, and 7. The results show that the maximum delamination occurs at a higher feed rate of $480 \mathrm{~mm} / \mathrm{min}$, whereas the delamination is minimum at a lower feed rate of $64 \mathrm{~mm} / \mathrm{min}$. The optimized results are obtained at higher drilling speeds and lower feed rates, as shown in Table 6 .

\subsection{DIC output graphs}

The three types of outputs are obtained from the Matlab Code, contour plot, line scan, and spatial average, and these three graphs are obtained for every specimen, to be explained below.

\subsubsection{Specimen \# 1}

The speed and feed combination for Specimen 1 is $1600 \mathrm{~mm} / \mathrm{min}$ and $64 \mathrm{~mm} / \mathrm{min}$, respectively, and $\mathrm{OHC}$

Table 4. Mean stresses for 1st, 2nd, and 3rd run.

\begin{tabular}{cccccccccc}
\hline Specimen \# & S1 & S2 & S3 & S4 & S5 & S6 & S7 & S8 & S9 \\
\hline 1st run & 314 & 225 & 259 & 309 & 288 & 251 & 306 & 306 & 303 \\
2nd run & 264 & 239 & 281 & 253 & 252 & 257 & 293 & 288 & 216 \\
3rd run & 320 & 288 & 315 & 351 & 267 & 263 & 268 & 297 & 216 \\
Mean stresses & 299 & 251 & 285 & 304 & 269 & 257 & 289 & 297 & 245 \\
\hline
\end{tabular}


Table 5. Comparison of speed, feed, and Open Hole Compression (OHC) strength.

\begin{tabular}{ccccccccccc}
\hline Drilling speed (S) & \multicolumn{2}{c}{$\mathbf{1 6 0 0}$} & $\mathbf{~ m m} / \mathbf{m i n}$ & \multicolumn{2}{c}{$\mathbf{2 4 0 0}$} & $\mathbf{~} \mathbf{m m} / \mathbf{m i n}$ & \multicolumn{3}{c}{$\mathbf{3 2 0 0} \mathbf{~} \mathbf{m m} / \mathbf{m i n}$} \\
\hline Feed (F), mm/min & $\mathbf{6 4}$ & $\mathbf{1 9 2}$ & $\mathbf{4 8 0}$ & $\mathbf{6 4}$ & $\mathbf{1 9 2}$ & $\mathbf{4 8 0}$ & $\mathbf{6 4}$ & $\mathbf{1 9 2}$ & $\mathbf{4 8 0}$ \\
OHC strength (N) & 26013 & 21837 & 24795 & 26448 & 23403 & 22359 & 25143 & 25839 & 21315 \\
\hline
\end{tabular}

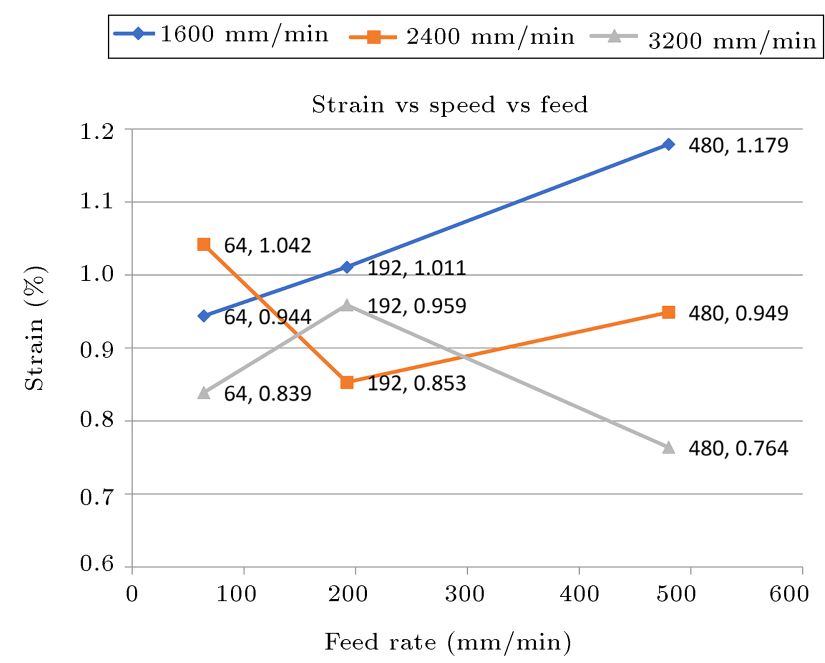

Figure 10. Relationship of strain, speed, and feed of Specimen 1.

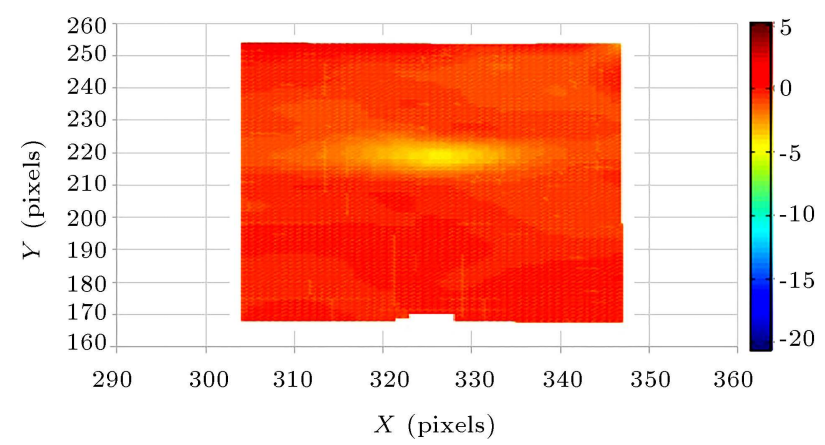

Figure 11. Contour plot of strain percentage for Specimen 1.

strength of $26013 \mathrm{~N}$ is given. The graph is shown in Figure 10 that represents the strain distribution in the selected area. The strain distribution is highlighted by colors. $X$ and $Y$ axes take the pixels as a location for strain distribution. The area selected for the DIC is divided into the pixels by the Matlab Code; the correlation is found by comparing the speckle patterns in each image; and the strain percentage graph, line scan, and spatial average are measured.

The contour strain plot in the $Y Y$ direction is shown in Figure 11 and strain percentage is given on the last correlated image. The yellow spot near the center shows the $-5 \%$ strains on that area. In Figure 11, the line scan of Specimen 1 shows the finite strain in the $Y Y$ direction along the horizontal line 0.5 from

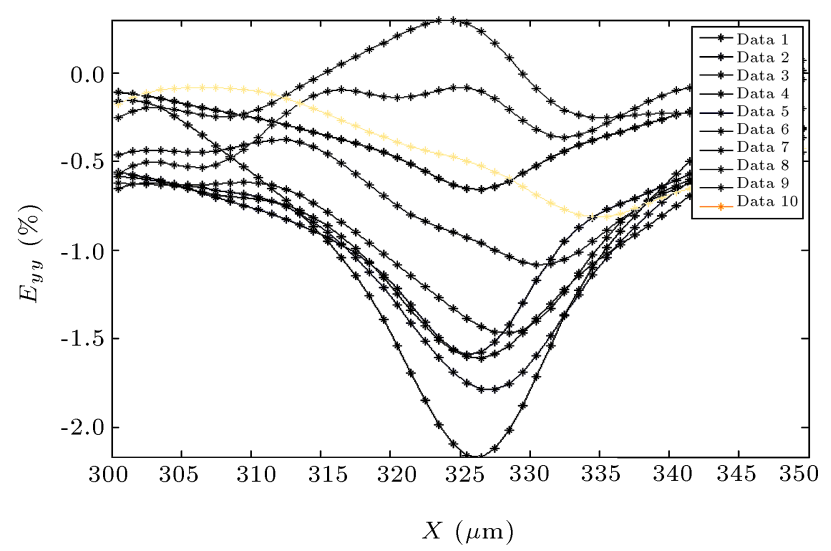

Figure 12. Line scan graph for Specimen 1.

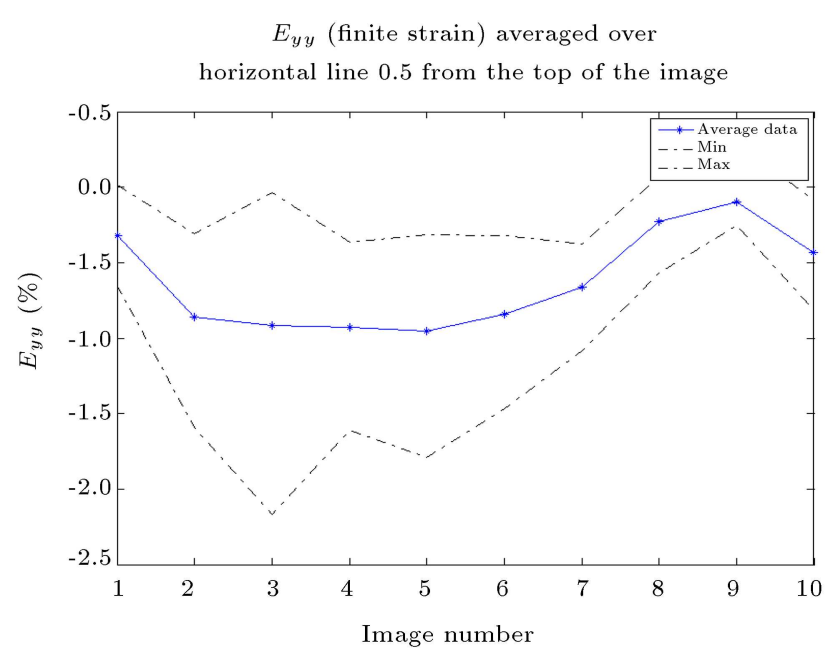

Figure 13. Spatial average graph for Specimen 1.

the top of the Region Of Interest (ROI). Each line shows the strain distribution for a single image. $X$ axis shows the pixel scale equal to $1 \mu \mathrm{m} /$ pixel. The legend represents every line color by the data series using the fading line color for every next image strain distribution. $Y$-axis represents the strain percentage. The lines are dropping in the center which shows the negative strain at the center of the ROI.

Figure 12 represents the spatial average of finite strain on the horizontal line 0.5 from the top of the image. The $X$-axis indicates the total number of images for the DIC and $Y$-axis for the strain percentage in the $Y Y$ direction. The graph shows that the strain increases in the negative direction for Figures 2 to 7 and then, it decreases to the last one, as shown in Figure 13. 
Table 6. Comparison of Open Hole Compression (OHC) strength with delamination.

\begin{tabular}{|c|c|c|c|c|}
\hline $\begin{array}{l}\text { Sr. } \\
\#\end{array}$ & $\begin{array}{c}\text { Drilling } \\
\text { parameter }\end{array}$ & $\begin{array}{c}\text { OHC } \\
\text { strength }\end{array}$ & Drill bit entry & Drill bit exit \\
\hline 1 & $1600 \& 64$ & 26013 & 8 & \\
\hline 2 & $1600 \& 192$ & 21837 & & \\
\hline 3 & $1600 \& 480$ & 24795 & & \\
\hline 4 & $2400 \& 64$ & 26448 & & \\
\hline 5 & $2400 \& 192$ & 23403 & & \\
\hline 6 & $2400 \& 480$ & 22359 & & \\
\hline 7 & $3200 \& 64$ & 25143 & & \\
\hline 8 & $3200 \& 192$ & 25839 & 9 & \\
\hline 9 & $3200 \& 480$ & 21315 & & \\
\hline
\end{tabular}




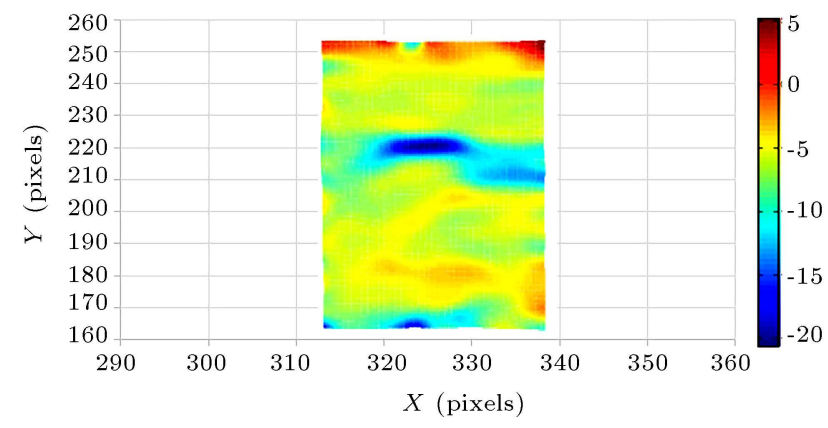

Figure 14. Contour plot of strain percentage for Specimen 2.

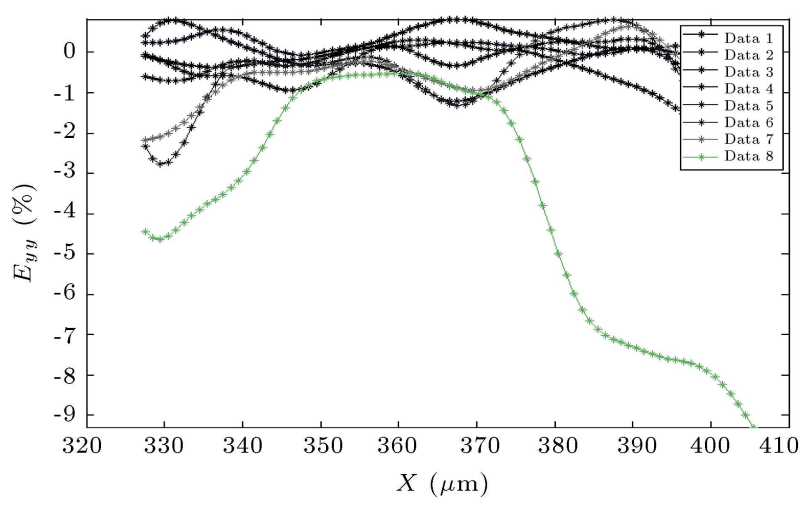

Figure 15. Line scan graph of Specimen 2.

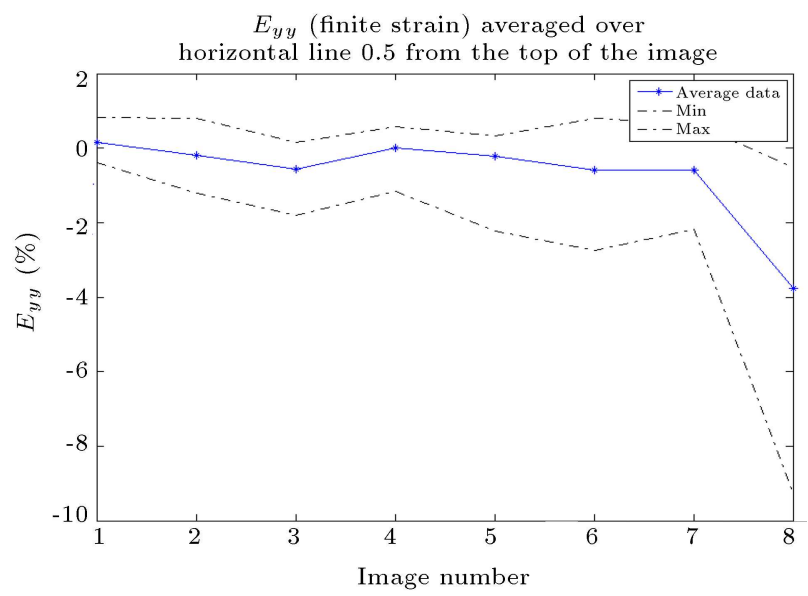

Figure 16. Spatial average graph of Specimen 2.

\subsubsection{Specimen \# 2}

The graph is shown in Figure 14, representing the contour plot of strain percentage for Specimen 2. The line scan graph of Specimen 2 is presented in Figure 15. The spatial average graph of Specimen 2 is depicted in Figure 16.

\subsubsection{Specimen \# 3}

The graph is shown in Figure 17 representing the contour plot of strain percentage for Specimen 3 . The line scan graph of Specimen 3 is shown in Figure 18.

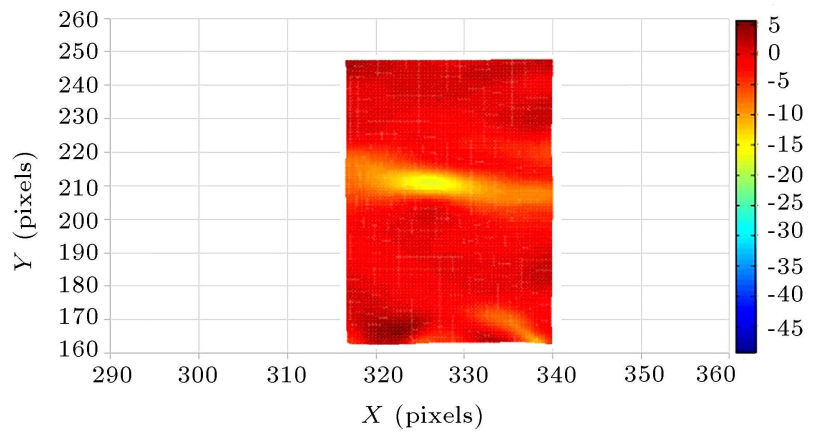

Figure 17. Contour plot of strain percentage for Specimen 3.

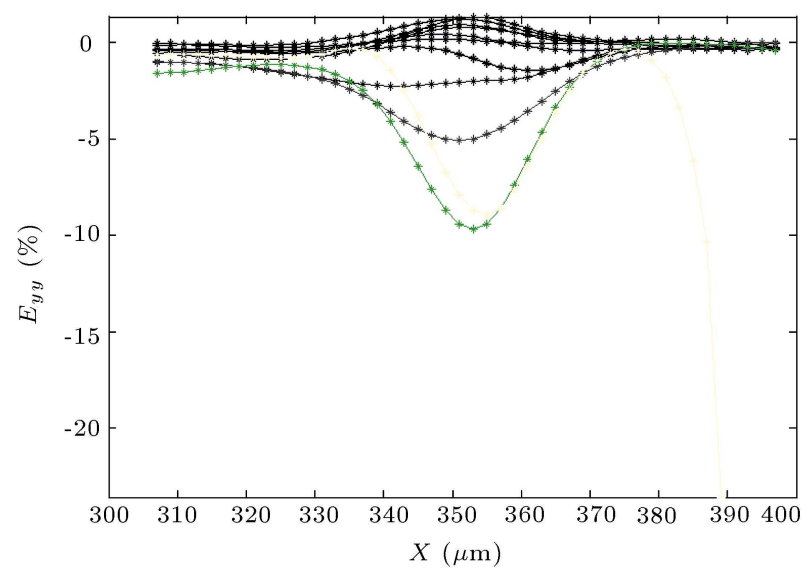

Figure 18. Line scan graph of Specimen 3.

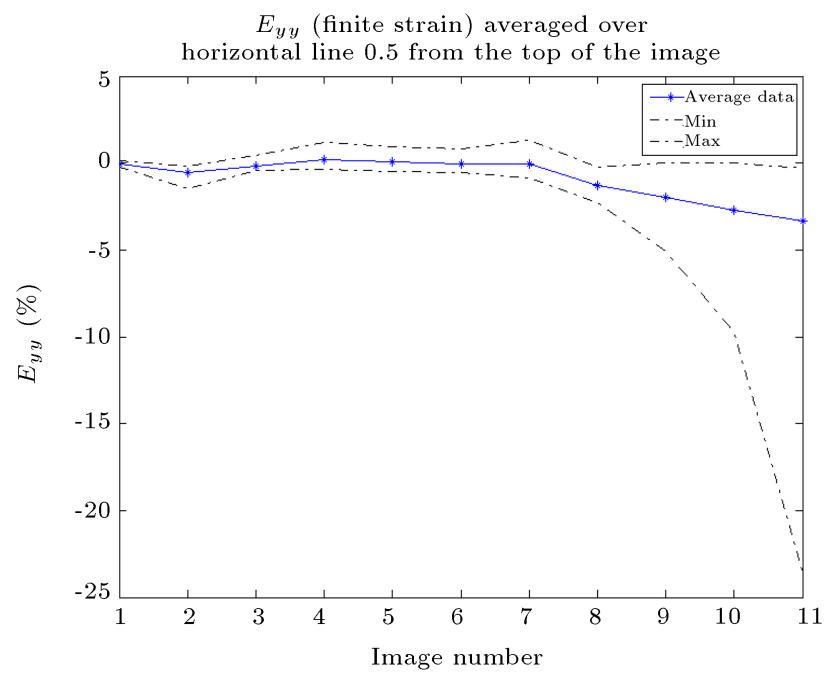

Figure 19. Spatial average graph of Specimen 3.

The spatial average graph of Specimen 3 is depicted in Figure 19.

\section{Limitations}

The testing standard technique applied in the current research is limited to continuous fibers. For discontin- 
uous fibers and laminates, fibers should be symmetric and balanced in the test direction over the course of conducting this test.

\section{Conclusion}

- Based on the experimental and Digital Image Correlation (DIC) results, it was concluded that the maximum strength for the carbon epoxy composite with its notch (hole) was achieved by drilling at the speed of 1600-2400 mm/min and low feed rates. The contour plots displayed the strain distribution around the hole;

- The strain percentage for the specimens with less Open Hole Compression (OHC) strength was higher due to the delamination and internal fiber pull-out. The line scan plot shows the strain distribution around the hole and the line illustrates the very compressive behavior around the hole;

- Four cutting methods, namely end mill cutter, hack saw, High Speed Steel (HSS) disc, and SiC abrasive disc, were employed to cut the composite sheet to pick out the best method out of them;

- The best cutting results were obtained by the $\mathrm{SiC}$ abrasive disc of $1 \mathrm{~mm}$ thickness;

- According to the experimental results, at higher feed rates, delamination was higher due to the chisel effect;

- Failure was dependent on the feed rate of drilling and the optimized drilling ranged from 1600 to $2400 \mathrm{~mm} / \mathrm{min}$;

- The OHC strength values were very close at all speeds and a feed rate of $64 \mathrm{~mm} / \mathrm{min}$. At higher feed rates, the strength values were minimum.

\section{Nomenclature}

$F_{x} \quad$ Compressive strength $(\mathrm{MPa})$

$P_{\max } \quad$ Maximum force $(\mathrm{N})$

A Gross cross-sectional area $\left(\mathrm{mm}^{2}\right)$

\section{References}

1. Imran, M., Khana, R., and Badshaha, S. "Investigating the effect of delamination size, stacking sequences and boundary conditions on the vibration properties of carbon fiber reinforced polymer composite", Materials Research, 22(2), pp. 1-7 (2019).

2. Imran, M., Khan, R., and Badshah, S. "Experimental, analytical, and finite element vibration analyses of delaminated composite plates", Scientia Iranica, 28(1), pp. 231-240 (2021).
3. Ahmadi, M., Ansari, R., and Rouhi, H. "Studying buckling of composite rods made of hybrid carbon fiber/carbon nanotube-reinforced polyimide using multi-scale FEM", Scientia Iranica, Transactions B, Mechanical Engineering, 27(1), pp. 252-261 (2020).

4. Bahl, S. "Axisymmetric finite element analysis of single fiber push-out test for stainless steel wire reinforced aluminum matrix composites", Materials Today: Proceedings, 28(3), pp. 1605-1611 (2020).

5. Bahl, S. and Bagha, A.K. "Finite element modeling of the fiber-matrix interface in polymer composites", Journal of Composites Science, 58(4), pp. 1-13 (2020).

6. Kim, T., Shin, J., Lee, K., Jung, Y., Lee, S.B., and Yang, S.J. "A universal surface modification method of carbon nanotube fibers with enhanced tensile strength", Composites Part A: Applied Science and Manufacturing, 140, pp. 1-5 (2021).

7. Mulenga, T.K., Ude, A.U., and Vivekanandhan, C. "Techniques for modelling and optimizing the mechanical properties of natural fiber composites: A review", Fibers, 9(1), pp. 1-17 (2021).

8. Imran, M., Rafiullah, K., and Badshah, S. "Vibration analysis of cracked composite laminated plate and beam structures", Romanian Journal of Acoustics and Vibration, 15(1), pp. 3-13 (2018).

9. Imran, M., Khan, R., and Badshah, S. "Finite element analysis to investigate the influence of delamination size, stacking sequence and boundary conditions on the vibration behavior of composite plate", Iranian Journal of Materials Science and Engineering, 16(1), pp. 2-9 (2019).

10. Bagha, A.K. and Bahl, S. "Finite element analysis of $\mathrm{VGCF} / \mathrm{pp}$ reinforced square representative volume element to predict its mechanical properties for different loadings", Materials Today: Proceedings, 39, pp. 54-59 (2021).

11. Imran, M., Khan, R., and Badshah, S. "A review on the vibration analysis of laminated composite plate", Pakistan Journal of Scientific \& Industrial Research Series A: Physical Sciences, 62(2), pp. 124-134 (2019).

12. Imran, M., Badshah, S., and Khan, R. "Vibration analysis of cracked composite laminated plate: A review", Mehran University Research Journal of Engineering and Technology, 38(3), pp. 705-716 (2019).

13. Muhammad, I., Rafiullah, K., and Saeed, B. "A review on the vibration analysis of laminated composite plate", Pakistan Journal of Scientific and Industrial Research Series A: Physical Sciences, 62(2), pp. 1218 (2019).

14. Saini, M.K., Bagha, A.K., Kumar, S., and Bahl, S. "Finite element analysis for predicting the vibration characteristics of natural fiber reinforced epoxy composites", Materials Today: Proceedings, 41, pp. 223227 (2021). 
15. Imran, M., Khan, R., and Badshah, S. "A review on the effect of delamination on the performance of composite plate", Pakistan Journal of Scientific \& Industrial Research Series A: Physical Sciences, 61(3), pp. 173-182 (2018).

16. Bagha, A.K. and Bahl, S. "Strain energy and finite element analysis to predict the mechanical properties of vapor grown carbon fiber reinforced polypropylene nanocomposites", Materials Today: Proceedings, 41, pp. 265-268 (2021).

17. Barbero, E.J.,Introduction to Composite Materials Design, CRC press (2017).

18. Malhotra, S. "Some studies on drilling of fibrous composites", Journal of Materials Processing Technology, 24, pp. 291-300 (1990).

19. Tagliaferri, V., Caprino, G., and Diterlizzi, A. "Effect of drilling parameters on the finish and mechanical properties of GFRP composites", International Journal of Machine Tools and Manufacture, 30(1), pp. 7784 (1990).

20. Hocheng, H. and Puw, H. "On drilling characteristics of fiber-reinforced thermoset and thermoplastics", International Journal of Machine Tools and Manufacture, 32(4), pp. 583-592 (1992).

21. Caprino, G. and Tagliaferri, V. "Damage development in drilling glass fibre reinforced plastics", International Journal of Machine Tools and Manufacture, 35(6), pp. 817-829 (1995).

22. Piquet, R., Ferret, B., Lachaud, F., and Swider, P. "Experimental analysis of drilling damage in thin carbon/epoxy plate using special drills", Composites Part A: Applied Science and Manufacturing, 31(10), pp. 1107-1115 (2000).

23. Lachaud, F., Piquet, R., Collombet, F., and Surcin, L. "Drilling of composite structures", Composite Structures, 52(3-4), pp. 511-516 (2001).

24. Davim, J.P. and Reis, P. "Drilling carbon fiber reinforced plastics manufactured by autoclaveexperimental and statistical study", Materials \& Design, 24(5), pp. 315-324 (2003).

25. Bhatkulkar, H. and Modak, J. "Design and development of nursery fertilizer mixer energized by human powered flywheel motor", International Journal For Research in Emerging Science and Technology, 1, pp. 69-73 (2014).

26. Rajmohan, T. and Palanikumar, K. "Application of the central composite design in optimization of machining parameters in drilling hybrid metal matrix composites", Measurement, 46(4), pp. 1470-1481 (2013).
27. Sadek, A., Meshreki, M., and Attia, M. "Characterization and optimization of orbital drilling of woven carbon fiber reinforced epoxy laminates", CIRP Annals, 61(1), pp. 123-126 (2012).

28. Phadnis, V.A., Makhdum, F., Roy, A., and Silberschmidt, V.V. "Drilling in carbon/epoxy composites: experimental investigations and finite element implementation", Composites Part A: Applied Science and Manufacturing, 47, pp. 41-51 (2013).

29. Karimi, N.Z., Heidary, H., Minak, G., and Ahmadi, M. "Effect of the drilling process on the compression behavior of glass/epoxy laminates", Composite Structures, 98, pp. 59-68 (2013).

30. Durão, L.M.P., Tavares, J.M.R., de Albuquerque, V.H.C., and Gonçalves, D.J. "Damage evaluation of drilled carbon/epoxy laminates based on area assessment methods", Composite Structures, 96, pp. 576$583(2013)$.

31. Feito, N., López-Puente, J., Santiuste, C., and Miguélez, M. "Numerical prediction of delamination in CFRP drilling", Composite Structures, 108, pp. 677683 (2014).

32. Qi, Z., Zhang, K., Li, Y., Liu, S., and Cheng, H. "Critical thrust force predicting modeling for delaminationfree drilling of metal-FRP stacks", Composite Structures, 107, pp. 604-609 (2014).

33. Goutianos, S., Galiotis, C., and Peijs, T. "Compressive failure mechanisms in multi-fibre microcomposites", Composites Part A: Applied Science and Manufacturing, 35(4), pp. 461-475 (2004).

34. Suemasu, H., Takahashi, H., and Ishikawa, T. "On failure mechanisms of composite laminates with an open hole subjected to compressive load", Composites Science and Technology, 66(5), pp. 634-641 (2006).

35. Saha, M., Prabhakaran, R., and Waters Jr, W. "Compressive behavior of pultruded composite plates with circular holes", Composite Structures, 65(1), pp. 29-36 (2004).

36. Poon, C., Bellinger, N., Gould, R., and Raizenne, M. "Damage progression nuder compressive loading in composite laminates containing an open hole", $\mathrm{Na}$ tional Research Council of Canada Ottawa (Ontario) Inst for Aerospace Research (1992).

37. Zako, M., Uetsuji, Y., and Kurashiki, T. "Finite element analysis of damaged woven fabric composite materials", Composites Science and Technology, 63(34), pp. 507-516 (2003).

38. Carvalho, N., Pinho, S., and Robinson, P. "Compressive failure of $2 \mathrm{D}$ woven composites", Proceedings of the 17th International Conference on Composite Materials, Edinburgh, UK: IOM Communications Ltd (2009).

39. Soutis, C., Fleck, N., and Smith, P. "Failure prediction technique for compression loaded carbon fibre-epoxy laminate with open holes", Journal of Composite Materials, 25(11), pp. 1476-1498 (1991).

40. Jones, E., Documentation for Matlab-based DIC code, University of Illinois (2013). 
41. PI, L.Y., Smith, L., Gothekar, M.A., and Chen, M.X., Measure Strain Distribution Using Digital Image Correlation (DIC) for Tensile Tests, Oakland University (2010).

\section{Biographies}

Muhammad Tayyab is a $\mathrm{PhD}$ candidate at the Mechanical Engineering Department at UET Taxila, Pakistan. He has been a Researcher at Composites Manufacturing Laboratory in UET Taxila since 2015. He currently works as a Lecturer at the Department of Mechanical Engineering, Faculty of Engineering and Technology, International Islamic University, Islamabad, Pakistan. His current research interests include the composites and simulations.

Muhammad Imran received the $\mathrm{PhD}$ degree in
Mechanical Engineering from the International Islamic University, Islamabad. He currently works as a Lecturer at the Department of Mechanical Engineering, Faculty of Engineering and Technology, International Islamic University, Islamabad, Pakistan. His current research interests include the material characterization, composites, vibrations, and finite element.
Abdur Rafai is a PhD candidate at the Department of Mechanical Engineering in the International Islamic University, Islamabad, Pakistan. He has been a Researcher in FEM in International Islamic University since 2013. He currently works as a Lecturer at the Department of Mechanical Engineering, Faculty of Engineering and Technology, International Islamic University, Islamabad, Pakistan. His current research interests include the finite element analysis, UTM, and composites. 